\title{
Team Work Employee Engagement dalam Pendampingan Operator Madrasah Di KKMI Tutur Pasuruan
}

\author{
Khoirul Anwar1) \\ Institut Agama Islam Sunan Kalijogo Malang \\ khoirulanwar@iaiskjmalang.ac.id
}

\begin{abstract}
Abstrak. Dengan semakin canggihnya teknologi, menuntut lembaga pendidikan khususnya madrasah mengikuti perkembangan utamanya di era digitalisasi saat ini. Madrasah yang kerap dibandingkan dengan sekolah sekarang tidak lagi ada perbedaan yang siignifikan antara keduanya, transformasi pendidikan madrasah sudah semakin menunjukkan kesiapan untuk bersaing secara professional dalam dunia pendidikan. Maka dari hal tersebut pembenahan terus digalakkan terlebih dalam sistem informasi manajemen madrasah sehingga secara tidak langsung merangsang madrasah yang berada di tingkat kecamatan ikut berbenah menghadapi tantangan pendidikan saat ini. Dari sinilah lahir komunitas baru yaitu operator madrasah yang berperan penting dalam mengawal sistem maupun aplikasi pendataan. Kinerja operator madrasah dinilai kurang maksimal saat lembaga berjalan secara individu, sehingga membutuhkan sebuah formula khusus agar efektifitas pendataan di madrasah tetap berjalan sesuai harapan kementerian agama. Melalui kegiatan pendampingan operator madrasah dengan metode Team Work Employee Engagement diharapkan mampu menjawab problem pendataan yang terkesan menuntut agar madrasah belajar secara mandiri dalam mengembangan maupun memahami aplikasi yang dibuat oleh kementerian. Dari metode ini terbukti membawa hasil yang maksimal, hal tersebut dibuktikan dengan solidnya para operator lembaga dalam mengawal pendataan yang awalnya bersifat individu dirubah menjadi kerja tim yang mampu meringankan beban madrasah utamanya dalam hal sistem informasi. Sehingga melalui kegiatan pendampingan ini madrasah mampu berbenah utamanya dalam hal administrasi karena peran operator madrasah sudah lebih maksimal dan terkoordinir dengan baik dalam mengawal proses pendataan yang ada di madrasah khususnya madrasah swasta di wilayah Kecamatan Tutur.
\end{abstract}

Kata Kunci: Madrasah, Team Work Employee Engagement, Operator Madrasah

Abstrak. With increasingly sophisticated technology, it requires educational institutions, especially madrasas, to follow the main developments in the current digitalization era. Madrasah, which are often compared to schools now, no longer have a significant difference between the two, the transformation of madrasa education has increasingly shown readiness to compete professionally in the world of education. Therefore, improvements continue to be encouraged, especially in the madrasa management information system so that it indirectly stimulates madrasas at the subdistrict level to take part in improving the current educational challenges. This is where a new community was born, namely madrasah operators who play an important role in overseeing the data collection system and application. The performance of madrasah operators is considered less than optimal when the institution runs individually, so it requires a special formula so that the effectiveness of data collection in madrasas continues to run according to the expectations of the ministry of religion. Through 


\section{Khidinatuina \\ Jurnal Penelitian dan Pengabdian Hepada Masularahat}

Institut Agama Islam Sunan Kalijogo Malang

P-ISSN: 2721-9607/ E-ISSN: 2721-947X

Volume 2 Nomor 1 Juli 2021

mentoring activities for madrasah operators with the Team Work Employee Engagement method, it is hoped that they will be able to answer the problem of data collection which seems to demand that madrasas learn independently in developing and understanding applications made by the ministry. This method is proven to bring maximum results, this is evidenced by the solidity of institutional operators in overseeing data collection which was originally an individual change into team work that is able to ease the burden on madrasas, especially in terms of information systems. So that through this mentoring activity, madrasas are able to improve mainly in terms of administration because the role of madrasa operators has been maximized and is well coordinated in overseeing the data collection process in madrasas, especially private madrasas in the Tutur District area.

\section{Keywords: Madrasah, Team Work Employee Engagement, Madrasah Operators}

\section{PENDAHULUAN}

Pendidikan merupakan aset penting bagi generasi saat ini dan generasi masa yang akan datang. Pendidikan memberi kita banyak pengetahuan tentang berbagai hal dan segala sesuatu yang berhubungan dengan dunia ini, pendidikan juga dapat memberikan pandangan bagi kehidupan. Membantu kita membentuk sudut pandang kehidupan sehingga pendidikan merupakan hal yang sangat penting dan tidak bisa lepas dari kehidupan. Manusia-manusia unggul, bermoral dan pekerja keras merupakan tuntutan dari masyarakat global, disinilah pendidikan mendapatkan tempat sekaligus tantangan dalam dinamika kehidupan masyarakat, karena pendidikan yang berkualitas memegang peran yang penting dalam peningkatan sumber daya manusia ${ }^{1}$. Salah satu isu penting dalam penyelenggaraan pendidikan saat ini adalah peningkatan mutu pendidikan, sehingga Undang- undang Nomor 20 tahun 2003 tentang Sistem Pendidikan Nasional pasal 4 ayat 6 menegaskan bahwa: Pendidikan diselenggarakan dengan memberdayakan semua komponen masyarakat melalui peran serta dalam penyelenggaraan dan pengendalian mutu layanan pendidikan ${ }^{2}$. Madrasah sebagai Lembaga Pendidikan Islam dituntut untuk dapat meningkatkan mutu lulusan selain mutu input- process- output dan outcame, keberadaan madrasah juga harus dilengkapi dengan berbagai fasilitas pembelajaran yang memadai, sehingga diharapkan madrasah akan selalu relevan dengan tuntutan dan kebutuhan masyarakat. ${ }^{3}$

\footnotetext{
${ }^{1}$ Wahir Tupono, "Efektivitas Education Management Information System (Emis) Di Madrasah Aliyah Negeri 5 Sleman," Jurnal Manajemen Publik \& Kebijakan Publik (JMPKP) 2, no. 1 (2020): 24-37.

2 Presiden Republik Indonesia, Undang-Undang Republik Indonesia Nomor 20 Tahun 2003 Tentang Sistem Pendidikan Nasional (Indonesia, 2003). Sleman."

3 Tupono, "Efektivitas Education Management Information System (Emis) Di Madrasah Aliyah Negeri 5
} 
Sistem informasi manajemen merupakan jaringan informasi yang dibutuhkan pimpinan dalam menjalankan tugasnya, terutama dalam mengambil keputusan. Sudah barang tentu kalau disebutkan "dibutuhkan pimpinan", berarti pula dibutuhkan juga oleh organisasi, sebab tugas pimpinan bukan untuk kepentingan dirinya sendiri, tetapi juga kepentingan organisasi dalam mencapai tujuan organisasi. ${ }^{4}$

Perkembangan sistem informasi manajemen menjadi sebuah perhatian khusus di dunia pendidikan, tak terkecuali perkembangan tersebut juga memberikan warna baru terhadap pengelolaan madrasah. madrasah adalah lembaga pendidikan yang menjadikan mata pelajaran agama Islam sebagai mata pelajaran dasar yang diberikan sekurang-kuranya $30 \%$ disamping mata pelajaran umum, meliputi Madrasah Ibtidaiyah setingkat dengan Sekolah Dasar, Madrasah Tsanawiyah setingkat SMP dan Madrasah Aliyah setingkat SMA. ${ }^{5}$ Madrasah yang berada di bawah naungan Kementerian Agama dari tahun ke tahun terus berbenah utamanya dalam hal sistem informasi manajemen, sehingga banyak sekali aplikasi pendataan yang ada di lingkungan madrasah seperti EMIS, SIMPATIKA, E-RKAM, BOS KEMENAG dan beberapa aplikasi lainnya yang tidak lain bertujuan mendukung proses perkembangan madrasah dalam mengembangan sistem informasinya.

Seiring berjalannya proses tersebut membuat madrasah akan sulit berkembang jika dalam hal pendataan hanya berpangku pada pendidik di madrasah, sehingga tugas tersebut sekarang diamanahkan pada operator madrasah, yaitu bagian dari tenaga kependidikan di madrasah yang bertugas khusus dalam menangani sistem informasi manajemen madrasah yang berbasis aplikasi. Dalam menjalankan tugas tersebut operator madrasah mulai terorganisir secara terstruktur mulai tingkat pusat kemenag, provinsi hingga di masingmasing lembaga.

Kecamatan Tutur merupakan sebuah wilayah yang berada di Kabupaten Pasuruan tepatnya berada di dataran menengah hingga dataran tinggi dengan ketinggian mulai $600 \mathrm{~m}$ dpl hingga $1000 \mathrm{~m}$ dpl dengan kondisi permukaan tanah yang berbukit sampai bergunung antara 20-30\%, memiliki 12 Desa yang terbagi habis menjadi 70 Dusun, 88 RW, 304 RT dengan

${ }^{4}$ S Damayanti and D A Rizal, "Pemanfaatan Sistem Informasi Pendidik Dan Tenaga Kependidikan (SIMPATIKA) Sebagai Dasar Pengambilan Keputusan Dan Kebijakan Di Kementerian Agama," Nusantara: Jurnal Pendidikan ... 1, no. 1 (2021): 77-94, https://journal.rumahindonesia.org/index.php/njpi/article/view/6.

5 Direktorat Jenderal Pendidikan Islam Kementerian Agama RI, "SEJARAH PENDIDIKAN ISLAM DAN ORGANISASI DITJEN PENDIDIKAN ISLAM," accessed July 9, 2021,

http://pendis.kemenag.go.id/index.php?a=artikel\&id2=sejarahpendis. 


\section{Khidinatuina \\ Jurnal Penelitian dan Pengabdian Hepada Masuarahat}

Institut Agama Islam Sunan Kalijogo Malang

P-ISSN: 2721-9607/ E-ISSN: 2721-947X

Volume 2 Nomor 1 Juli 2021

memiliki luas $86,315 \mathrm{~km}$ pesergi, dalam peta statistik pendidikan di Kecamatan Tutur lembaga SD/MI menjadi lembaga terbanyak dengan presentase $44,46 \%{ }^{6}$.

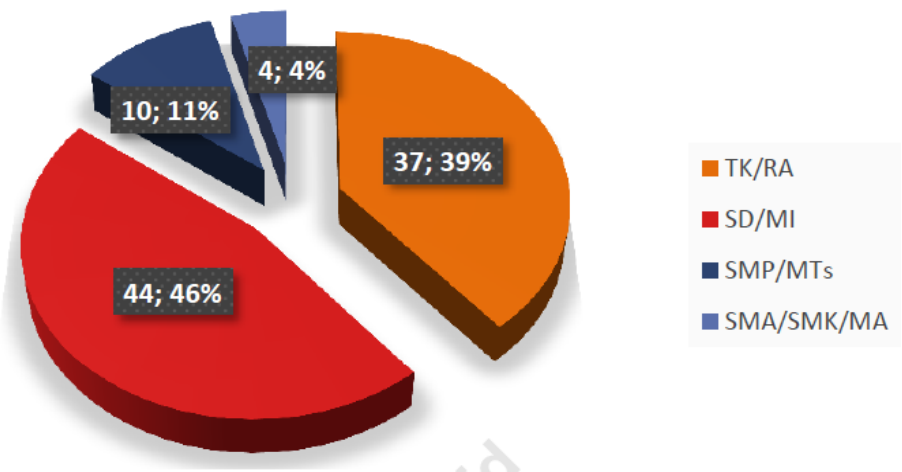

Gambar 1.1 Jumlah lembaga pendidikan dirinci menurut tingkatannya

Dari statistik di atas fokus pendampingan ini dilaksanakan pada lembaga Madrasah Ibtidaiyah di Kecamatan Tutur yang memiliki 13 Madrasah Ibtidaiyah Swasta yang tersebar di di 9 Desa dengan rincian Andonosari 2 MI, Pungging 1 MI, Kayukebek 1 MI, Blarang 1 MI, Tlogosari 1 MI, Tutur 2 MI, Kalipucang 1 MI, Sumberpitu 1 MI dan Ngembal 2 MI 7.

Berikut ini daftar lengkap MI Swasta se Kecamatan Tutur: ${ }^{8}$

\begin{tabular}{|c|c|c|c|c|}
\hline No. & NPSN & Nama Satuan Pendidikan & Alamat & Kelurahan \\
\hline 1 & $\underline{60730100}$ & MIS DARUL ULUM ARJOSARI & DUSUN ARJOSARI & ANDONO SARI \\
\hline 2 & 60716908 & MIS DARUL ULUM BADUT & BANDUT & NGEMBAL \\
\hline 3 & $\underline{60716912}$ & MIS MIFTAHUL ULUM & $\begin{array}{l}\text { JL. SIMPANG TIGA DUSUN } \\
\text { KUNTUL }\end{array}$ & KALI PUCANG \\
\hline 4 & 60716915 & MIS MIFTAHUL ULUM & $\begin{array}{l}\text { JLN. CEMORO PUNGGING } \\
\text { RT. } 03 \text { RW. } 02\end{array}$ & PUNGGING \\
\hline 5 & $\underline{60716914}$ & $\begin{array}{l}\text { MIS MIFTAHUL ULUM } \\
\text { ANDONOSARI }\end{array}$ & JL. MASJID AL IKHLAS & ANDONO SARI \\
\hline 6 & $\underline{60716910}$ & $\begin{array}{l}\text { MIS MIFTAHUL ULUM } \\
\text { BANYUSARI }\end{array}$ & $\begin{array}{l}\text { JL. BANYUSARI RT/RW } \\
01 / 01\end{array}$ & BLARANG \\
\hline 7 & $\underline{60716913}$ & $\begin{array}{l}\text { MIS MIFTAHUL ULUM KELEK } \\
\text { NGEMBAL }\end{array}$ & $\begin{array}{l}\text { DSN. GARUTAN } \\
\text { PEDUKUAN KELEK }\end{array}$ & NGEMBAL \\
\hline 8 & $\underline{69726223}$ & MIS MIFTAHUL ULUM TAMAN & $\begin{array}{l}\text { RT. } 05 \text { / RW. } 02 \text { DUSUN } \\
\text { TAMAN }\end{array}$ & KAYU KEBEK \\
\hline
\end{tabular}

${ }^{6}$ Seksi Integrasi Pengolahan dan Diseminasi Statistik, “Kecamatan Tutur Dalam Angka 2018," Peta Wilayah Kecamatan Tutur (BPS Kabupaten Pasuruan, 2018).

7 Direktorat Jenderal Pendidikan Islam, “EMIS DASHBOARD,” Kementerian Agama RI, last modified 2020, accessed July 12, 2021, http://emispendis.kemenag.go.id/dashboard/?content=datastatistik\&action=kab\&prov=35\&kab=14.

${ }^{8}$ Kementerian Pendidikan dan Kebudayaan, "DATA REFERENSI PENDIDIKAN," Pusat Data Dan Teknonologi Informasi, last modified 2020, accessed July 12, 2021,

https://referensi.data.kemdikbud.go.id/index11.php?level=3\&kode=051902\&id=9. 


\begin{tabular}{|c|llll}
\hline 9 & $\underline{60716918}$ & $\begin{array}{l}\text { MIS MIFTAHUL ULUM } \\
\text { TLOGOSARI }\end{array}$ & JL. MASJID AL ULA NO.15 & TLOGOSARI \\
\hline 10 & $\underline{60716909}$ & $\begin{array}{l}\text { MIS MIFTAHUL ULUM TUTUR } \\
\text { TIMUR }\end{array}$ & $\begin{array}{l}\text { DUSUN TUTUT WETAN } \\
\text { RT 04 RW 01 }\end{array}$ & TUTUR \\
\hline 11 & $\underline{60716916}$ & MIS NURUL HUDA & JL. RAYA SUMBER PITU & SUMBER PITU \\
12 & $\underline{69854270}$ & $\begin{array}{l}\text { MIS NURUL HUDA SUGRO } \\
\text { ANDONOSARI }\end{array}$ & $\begin{array}{l}\text { BROMO KM.20 RT.03 } \\
\text { RW.02 DUSUN SUGRO }\end{array}$ & ANDONO SARI \\
13 & $\underline{60716922}$ & MIS SUNAN AMPEL & KADIPATEN TUTUR & TUTUR \\
\hline
\end{tabular}

lembaga MI berusaha menjadi lembaga pendidikan berbasis madrasah yang mampu menjalankan sistem informasi manajemen madrasah. Peran operator madrasah menjadi sangat vital sejak diberlakukannya EMIS sebagai pusat data madrasah. Penulis menjadi sosok yang terlibat dalam pendampingan operator madrasah mengolah data dan berusaha menjadikan tingkat validitas data bisa dipertanggung jawabkan. Maka operator madrasah bukanlah tugas yang mudah karena harus mampu beradaptasi dengan tingkat kerumitan data yang terkadang setiap semester mengalami perubahan, tetapi hal tersebut tidak membuat pejuang data madrasah berputus asa tetapi kegiatan ini menjadikan pengelolahan lembaga madrasah lebih administratif dan siap menuju standar madrasah yang sesuai dengan harapan pemerintah khususnya Kementerian Agama.

Setiap madrasah memiliki satu orang yang bertugas sebagai operator yang memiliki tanggung jawab atas penggunaan sistem dan aplikasi pendataan, seperti memasukkan dan memperbaharui data madrasah dan data peserta didik serta mengirimkan data-data tersebut secara online maupun offline, kemudian dilakukan sinkronisasi untuk masuk kedalam basis data server pusat kementerian agama. Keberadaan tenaga administrasi atau disebut juga operator sangat berpengaruh untuk keberlangsungan lembaga sekolah dan meningkatkan mutu madrasah.

Pengelolaan sistem data pendidikan Madrasah dilakukan oleh kepala Madrasah yang bertanggung jawab terhadap kerahasiaan seluruh data Madrasah. Untuk mengelola data Madrasah, kepala Madrasah memerlukan peran Operator yang aktif, dapat dipercaya, dan handal dalam memberikan layanan data secara administrasi untuk menunjang segala aktivitas Madrasah yang lengkap dan mudah dipahami oleh pihak-pihak yang berkepentingan.

Operator madrasah merupakan petugas yang ditunjuk sekolah untuk melakukan input data. Operator Madrasah memegang peranan yang penting dalam melakukan pendataan dan sekaligus pengguna dari aplikasi dan sistem informasi manajemen madrasah dari kementerian agama maupun dinas pendidikan. Petugas operator memegang peran yang sangat penting 
dalam mengolah data maupun verifikasi dan validasi data. Tugas dan tanggung jawab operator melakukan pembaharuan data secara terus menerus sesuai kondisi di lembaga dan melakukan pelaporan dana Bantuan Operasional Sekolah (BOS). Salah satu kriteria utama diangkat menjadi operator sekolah adalah orang yang setidaknya menguasai IT dan tahu cara mengoperasikannya. ${ }^{9}$

Di sisi lain Operator Madrasah memiliki peran dan tugas yang sangat penting untuk mengelola sistem data Madrasah yang cepat dan akurat dimana mereka bertugas dalam berbagai bidang baik bekerjasama dengan kepala Madrasah, guru ataupun mereka bekerja sendiri. Peran Operator Madrasah adalah sebagai pengelola administrasi Madrasah dengan menggunakan aplikasi EMIS, SIMPATIKA, EDM dan lainnya yaitu berkaitan dengan data siswa, data pendidik dan tenaga kependidikan, persuratan, arsip, administrasi sarana dan prasarana, dan administrasi keuangan. Tugas Operator Madrasah menjadi tim pengelola dan sebagai bahan pengambilan keputusan. Semakin tepat data yang diberikan oleh Operator Madrasah maka akan semakin tinggi kepuasan pengguna data salah satunya adalah guru Madrasah. Penggunaan data Operator Madrasah oleh para guru Madrasah merujuk dari sistem SIMPATIKA mulai dari Riwayat Pegawai, Riwayat Pendidikan, Riwayat Mengajar, Fungsi dan Jabatan, Pengaturan Jadwal Mingguan, NRG (Nomor Registrasi Guru), Pengaktifan kolektif (s25), dan penerbitan SKMT (Surat Keterangan Melaksanakan Tugas) dan SKBK (Surat Keterangan Beban Kerja) online yang digunakan untuk pemberkasan TPG (Tunjangan Profesi Guru). ${ }^{10}$

Permasalahan yang sering dihadapi adalah kurang fahamnya cara kerja aplikasi yang didapat dari kementerian, sehingga perlu adanya pendampingan dalam memecahkan dan mempermudah lembaga menyelesaikan pendataan, maka melalui forum operator, pendamping berusaha membantu semaksimal mungkin bagaimana agar madrasah mampu mengimplementasikan data yang akuran dan valid demi kelancaran lembga. Harapan yang diinginkan dalam kegiatan pendampingan ini adalah madrasah bisa lebih mandiri dalam mengelolah sistem informasi khususnya dalam bidang pendataan selain itu dengan kerja tim operator akan lebih meminimalisir kesaalahan-kesalahan dalam pendataan yang tujuannya adalah kevalidan data madrasah yang bisa dipertanggung jawabkan.

\footnotetext{
${ }^{9}$ Henki Bayu Seta and Theresiawati Theresiawati, “Pelatihan Dan Pendampingan Aplikasi Data Pokok Pendidikan Untuk Operator Sekolah Pendidikan Anak Usia Dini," JURNAL ABDIMAS BSI 4, no. 1 (2021): 75-82.

10 Sri Erny Muliyani and Hj. Husnul Jannah, "Pengaruh Kualitas Pelayanan Operator Madrasah Terhadap Kepuasan Kerja Guru Madrasah Aliyah Plus Nurul Islam Sekarbela Kota Mataram," in Prosiding Seminar Nasional Lembaga Penelitian Dan Pendidikan (LPP) Mandala Tema Membangun Pendidikan Yang Mandiri Dan Berkualitas Pada Era Revolusi Industri 4.0 (Mataram: Universitas Muhammadiyah Mataram, 2018), 393-404.
} 


\section{METODE PELAKSANAAN KEGIATAN}

Team Work Employee Engagement adalah istilah kerja tim yang menjadi metode dalam kegiatan pendampingan ini dalam rangka berusaha meningkatkan efektifitas kinerja operator madrasah dalam mengawal sistem informasi manajemen di madrasah.

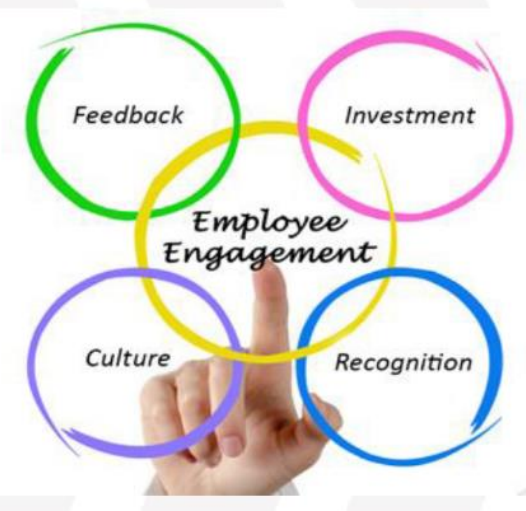

Gambar 2.1 Sistem informasi manajemen di madrasah

Istilah employee engagement pertama kali dipopulerkan oleh Kahn (1990), beliau menyatakan bahwa employee engagement sebagai keterikatan anggota organisasi dengan organisasi itu sendiri bukan hanya secara fisik, kognitif tetapi bahkan secara emosional dalam hal kinerjanya.

Operator madrasah menurut pandangan pendamping termasuk tipe pegawai lembaga pendidikan yang nomor 01 (Engaged), mengapa dikatakan seperti itu? Hubungan operator madrasah dengan lembaga tidak terbatas pada jam sekolah saja, tetapi ibarat khadam (abdi ndalem kyai) kapanpun dibutuhkan harus selalu siap siaga, dari hal tersebut lembaga menjadi sebuah tugas wajib yang sulit untuk ditinggalkan.

Jumlah lembaga MI di Kecamatan Tutur berjumlah 13 sehingga dalam kegiatan ini pendamping membuat tim yang berjumlah 13 orang dimana penulis sebagai fasilititor sekaligus pendamping kegiatan pendataan di madrasah, media group Whatsapp dijadikan sebagai sarana komunikasi dalam menyelesaikan segala masalah yang ada di pendataan sehingga apa yang menjadi kendala terkait system informasi manajemen di madrasah bisa segera terselesaikan.

Metode Team Work employee engagement adalah sebuah gagasan pendamping dalam kegiatan ini, metode ini digagas bagaimana kerja tim ditumbuhkan dengan keterikatan anggota organisasi dengan organisasi itu sendiri bukan hanya secara fisik, kognitif tetapi bahkan secara emosional dalam hal kinerjanya. Maka metode ini adalah upaya meringankan beban lembaga dalam mengolah pendataan. 


\section{Khidinatuina \\ Jurnal Penelitian dan Pengabdian Hepada Masuarahat}

Institut Agama Islam Sunan Kalijogo Malang

P-ISSN: 2721-9607/ E-ISSN: 2721-947X

Volume 2 Nomor 1 Juli 2021

Adapun tahapan yang dilakukan dalam pendampingan ini, pertama pendamping terjun langsung sebagi pelaku dalam kegiatan operator madrasah, kedua membangun komunikasi yang intraktif dengan semua operator lembaga melalui Group WA, ketiga pendamping membentuk tim khusus yang bertugas mempelajari secara detail aplikasi dari kemenag untuk di Redesign dengan tujuan memudahkan operator lembaga yang lain, keempat mengerjakan aplikasi secara bersama-sama dengan panduan yang telah ditetapkan dari operator tingkat provinsi maupun kabupaten selanjutnya didiskusikan apa yang menjadi kendala masingmasing lembaga untuk dipecahkan secara bersama, kelima penyelesaian akhir kinerja operator madrasah serta melaporkan progress dari masing-masing lembaga sebagai bentuk tanggung jawab kelembagaan.

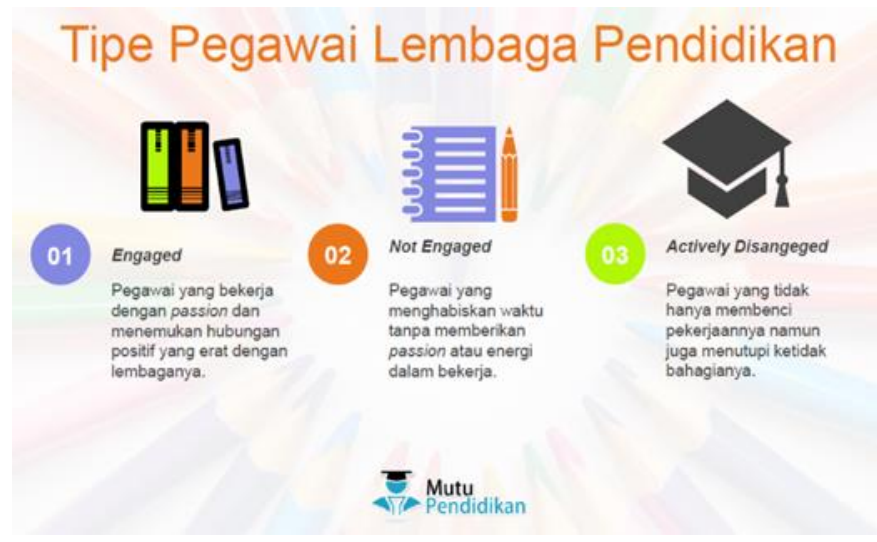

Gambar 2.2 Tipe pegawai Lembaga Pendidikan

\section{HASIL DAN PEMBAHASAN}

Teamwork adalah kumpulan orang-orang yang mampu bekerjasama dalam sebuah tim, setiap orang memiliki derajat yang sama dan penting dalam organisasi. Setiap individu berhubungan dengan individu lain melalui seorang pemimpin yang ditetapkan (Hughes, 1988). Sedangkan menurut Jhonsosn (2000) teamwork adalah sebuah jalan penting untuk menaikkan efektifitas organisasi. Teamwork adalah sekumpulan keterampilan yang dibutuhkan untuk dikembangkan selama latihan (Levi, 2001). Pendapat lain juga dikemukakan oleh Johlke (2002) yang menyatakan bahwa teamwork merupakan perbuatan dua orang atau lebih yang bekerja sama ke arah tujuan umum, saling membagi waktu, bakat, dan pengetahuan dan menggunakan metode yang cocok untuk semua anggota tim. Pada intinya teamwork adalah kemampuan individu untuk melakukan kerjasama dengan baik yang saling berhubungan satu sama lain dan giat bekerja, yang di dalamnya mengandung unsur kepercayaan, kejujuran, 
saling percaya, mendukung, serta bertanggungjawab dalam menjalankan tugas-tugas untuk mencapai tujuan bersama.

Sumber daya manusia yang saat ini dibutuhkan adalah sumber daya manusia yang memiliki work egagement yang optimum terhadap tujuan organisasi sehingga dapat tercapai tujuan organisasi, keberhasilan tujuan organisasi sangat dipengaruhi oleh work engagement sumber daya manusia terutama para operator madrasah ${ }^{11}$.

Work engagement adalah sebuah motivasi dan pusat pikiran positif yang berhubungan dengan pekerjaan yang dapat dicapai oleh seseorang atau kelompok orang dalam organisasi, sesuai dengan wewenang dan tanggung jawab masing-masing, dalam rangka mencapai tujuan organisasi bersangkutan secara legal, tidak melanggar aturan dan sesuai dengan moral dan etika. Tercapainnya tujuan organisasi hanya dimungkinkan karena upaya para pelaku yang terdapat organisasi tersebut. ${ }^{12}$

Kinerja operator madrasah bukan sebuah pekerjaan yang bisa diatur dengan waktu, sehingga terkadang untuk menghindari loading dari sebuah aplikasi tak jarang para operator lebih banyak beraktifitas di tengah malam, karena hal tersebut dirasa lebih efektif dan bisa lebih maksimal dalam pengerjaannya.

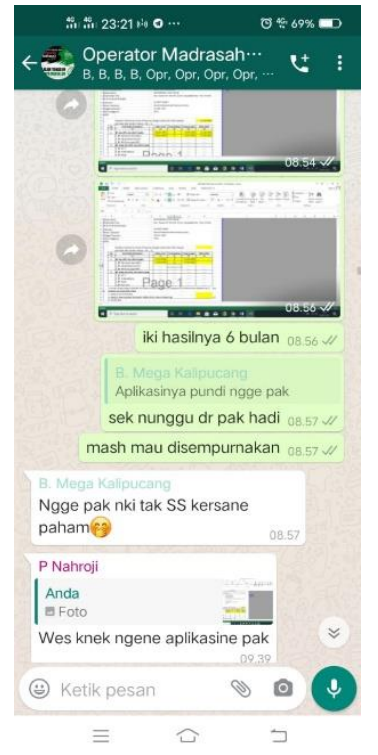

Pendamping dalam hal ini selalu menggunakan media group whatsaap dalam berkomunikasi secara intens terkait pendataan di madrasah, dalam group tersebut komunikasi terjalin layaknya berkumpul, sehinga efektifiktas berkaitan pendataan di madrasah bisa dimaksimalkan. File dokumen juga lebih banyak tersampaikan lewat group ini, maka metode Team Work employee engagement menjadi sangat efektif karena ikatan emosional yang terbangun menjadi modal utama dalam keberhasilan operator menyelesaikan tugasnya. Disisi lain adanya group tersebut juga dijadiakan ajang hiburan dengan candaan ala operator yg bertujuan menghilangkan rasa penat karena terlalu sering dibuat emosi oleh aplikasi yang tidak sesuai harapan.

11 Meri Susanti.R, Slamet Widodo, and Praningrum, "PENGARUH KEPEMIMPINAN DAN KEPRIBADIAN TERHADAP WORK ENGAGEMENT TENAGA KEPENDIDIKAN,” al-Bahtsu Vol. 4, no. No. 2 Desember (2019): 166175.

12 Ibid. 


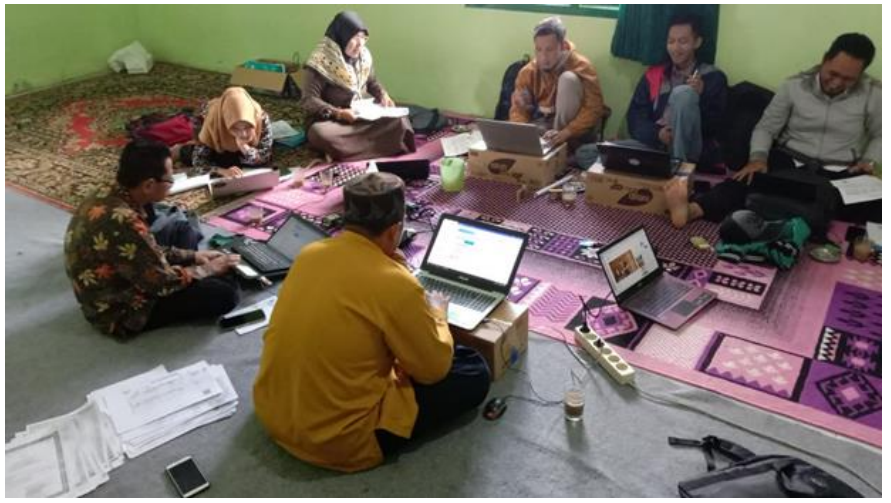

Gambar 3.1 Kegiatan Forum DIskusi

Kegiatan Forum DIskusi menjadi rutinitas yang harus dilakukan, karena aplikasi yang diberikan dari pusat sampai ke kabupaten, selanjutnya dari kabupaten diteruskan di tingkat kecamatan sering adanya ketidak sinkronan informasi yang di dapat, sehingga sebelum diselesaikan pekerjaan yang diminta terlebih dahulu kita diskusikan antar sesame operator, hal ini menjadi salah satu wadah untuk belajar bersama terkait aplikasi sistem informasi madrasah. Dengan kegiatan ini pendamping berhasil membuat lembaga-lembaga lebih percaya diri dan semua pasti bisa diselesaikan dengan kerja tim. Kegiatan semacam ini menjadikan madrasah lebih mandiri dan mengubah pola pikir yang dulu lebih suka pendataan itu menyuruh orang lain dengan jaminan upah, tetapi setelah adanya kegiatan pendampingan ini sedikit demi sedikit madrasah sudah mulai mandiri dalam hal pendataan. Inilah manfaat yang bisa dirasakan sehingga madrasah bisa belajar lebih baik bagaimana mengolah sistem informasi yang ada pada madrasah.

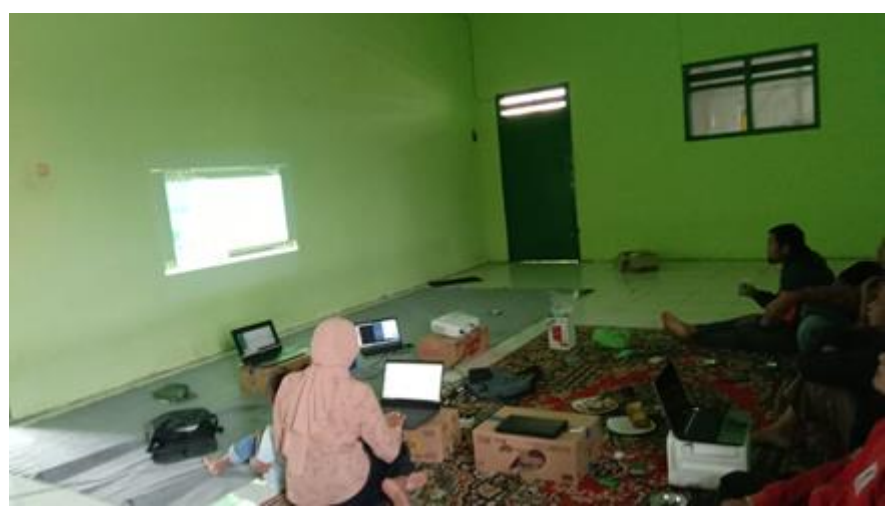

Gambar 3.1 operator madrasah KKMI

Kinerja operator madrasah KKMI Tutur dirasa sangat efektif karena tim selalu bekerja sama dalam menyelesaikan pendataan yang ada pada madrasah. Metode Team Work employee engagement mampu menjadikan kita layaknya keluarga, saling membantu antar lembaga, sehingga target setiap ada pendataan, semua lembaga MI yang ada di Kecamatan Tutur tidak 


\section{Khidinatuina \\ Jurnal Penelitian dan Pengabdian Hepada Masuarahat}

Institut Agama Islam Sunan Kalijogo Malang

P-ISSN: 2721-9607/ E-ISSN: 2721-947X

Volume 2 Nomor 1 Juli 2021

ada yang tertinggal, pendamping menginspirasi Team Work employee engagement bukan tidak lain mengambil pengertian bahwasanya sebuah organisasi yang memiliki ikatan emosional yang kuat hal tersebut senada dengan pengertian employee engagement sebagai keterikatan anggota organisasi dengan organisasi itu sendiri bukan hanya secara fisik, kognitif tetapi bahkan secara emosional dalam hal kinerjanya. Ini terbukti di kumpulan operaor madrasah secara mandiri memiliki tanggung jawab bagaimana perjalanan madrasah tidak terhambat dengan aplikasi.

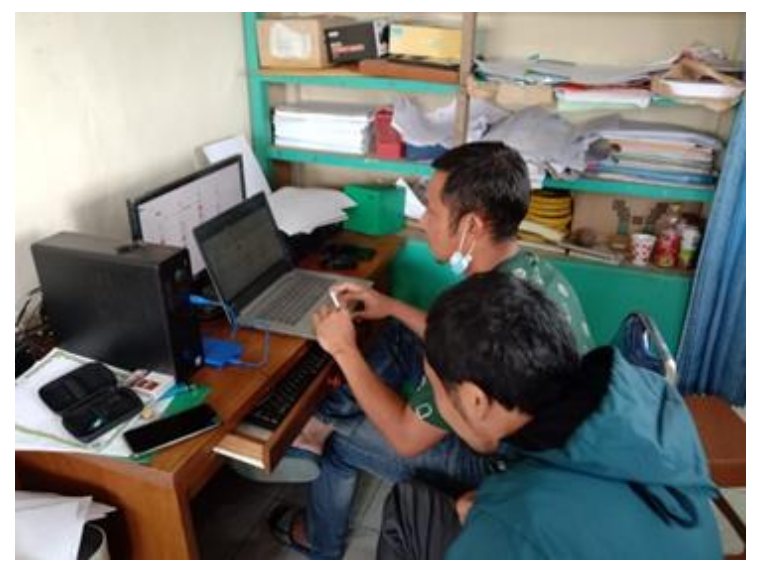

Gambar 3.3 Team Work employee engagement

Metode Team Work employee engagement juga ditunjukkan dengan bagaimana usaha memudahkan operator lembaga dalam pengerjaan aplikasi, pendamping dalam hal ini membentuk tim khusus sebagai fasilitator kepada operator lain, karena tidak semua aplikasi yang didapatkan dari kemenag itu berupa aplikasi yang simple, sehingga tim khusus ini bertugas mempelajari dan mengolah aplikasi yang ada agar bisa di redesign untuk lebih memudahakan lembaga. Salah satu contoh adalah aplikasi BOS Madrasah yang saat ini langsung dari pusat ke lembaga, maka disini pendamping dan tim khusus mengelola ulang aplikasi dari pusat untuk bisa dipermudah pengerjaannya oleh lembaga.

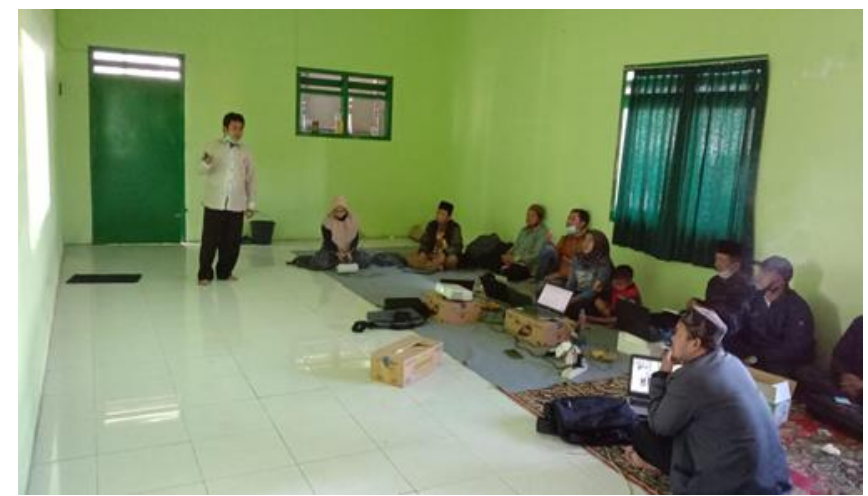

Gambar 3.4 Pendamping dan tim khusus mengelola ulang aplikasi dari pusat 
Kinerja para operator madrasah tidak lepas dari persetujuan dan pantauan kepala madrasah, oleh karena itu, pendamping bertanggung jawab melaporkan hasil team work kepada kepala madrasah dan pengawas madrasah. Ini dilakukan sebagai bentuk tanggung jawab kegiatan ini merupakan bagian dari manajemen madrasah di bidang pendataan. Karena dalam aturan organisasi pendidikan, operator madrasah hanya sebagai pelaksana tugas lapangan sedangkan kebijakan dan wewenang tetap ada pada kepala madrasah, maka sekalipun secara teknis ada di operator madrasah, tetapi secara kelembagaan tanggung jawab ada pada kepala madrasah. Maka kepala madrasah dituntut untuk faham terhadap sistem yang dikerjakan oleh operator, employee engagement disini muncul bahwa operator madrasah berusaha mensinkronkan pekerjaan dengan kebijakan para kepala madrasah, sehingga kesan kepala hanya terima jadi dari pekerjaan operator tidak akan terjadi, karena dengan penyampaian hasil ini, secara tidak langsung kepala juga akan belajar dan bisa memahami sejauh mana kualitas kinerja para operator dan hal ini dijadikan sebagai bahan evaluasi untuk memperbaiki kualitas team work yang dilakukan.

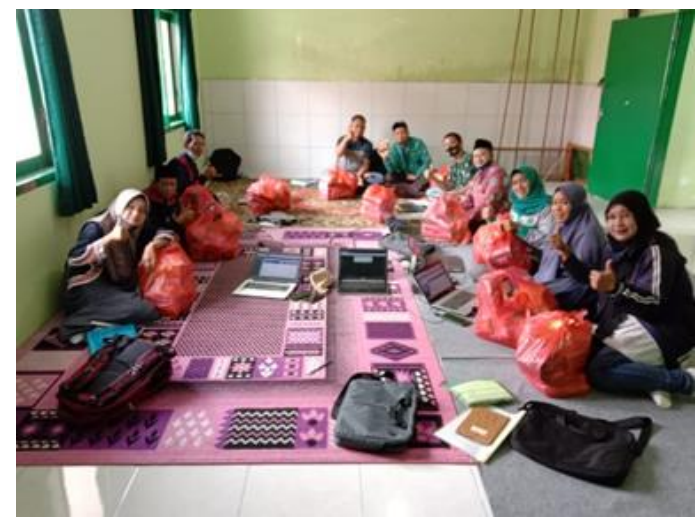

Gambar 3.5 Operator madrasah

Faktor keberhasilan Team Work employee engagement juga terjadi dengan ada reward yang diberikan oleh kepala madrasah sebagai bentuk apresiasi terhadap kerja keras operator dalam memperjuangkan data madrasah. Secara nilai mungkin terlalu kecil, tetapi bentuk perhatian itulah yang menjadikan secara emosional hubungan operator dengan lembaga terjalin. Reward berpengaruh langsung positif dan signifikan terhadap Work Engagement. Reward berkontribusi terhadap penciptaan Work Engagement operator madrasah agar bisa terus dipelihara dan ditingkatkan, baik dalam dimensi transactional maupun relational. Aspek yang harus dipelihara adalah learning and development, sedangkan aspek yang harus ditingkatkan adalah benefits dan work environment. Kondisi ini terlihat secara empirik pada KKMI Tutur, yang mana para kepala madrasah tidak menutup mata terhadap kinerja operator 


\section{Khidinatuina \\ Jurnal Penelitian dan Pengabdian Hepada Masuarahat}

Institut Agama Islam Sunan Kalijogo Malang

P-ISSN: 2721-9607/ E-ISSN: 2721-947X

Volume 2 Nomor 1 Juli 2021

madrasah. Mengacu pada uraian di atas, dapat disimpulkan bahwa secara empirik adanya pengaruh reward terhadap work engagement. ${ }^{13}$

\section{SIMPULAN}

Proses pendampingan operator madrasah dengan metode team work employee engagement menjadikan sebuah kegiatan yang efektif untuk kinerja operator madrasah, dimana dari kegiatan tersebut sedikit beban operator madrasah terkurangi, karena semua permasalahan yang terjadi dalam pendataan akan dipecahkan secara bersama-sama. Keuntungan yang didapat adalah rasa ikatan kerja yang kuat dengan tujuan bagaimana madrasah bisa terus berkembang dan menunjukan tingkat validitas pendataan yang akurat. Kegiatan pendampingan ini juga berdampak terhadap kreatifitas para operator dalam mengolah berbagai macam aplikasi, dengan cara otodidak kerja tim yang dibangun dapat membuat sistem informasi dan pendataan pada madrasah teratasi.

team work employee engagement menjadikan Persepsi operator madrasah mengenai pentingnya tugas di madrasah, selain itu rasa tanggung jawab atas kejelasan informasi menjadi prioritas dalam jalannya proses pendataan, disisi lain Feedback dan dialog berkala dengan kepala madrasah lebih akurat dengan adanya hasil nyata kinerja operator selain itu Hubungan yang berkualitas antara temankerja, atasan dan bawahan terjalin lantaran komunikasi yang efektif dilakukan demi perkembangan madrasah.

13 M Sidik Sisdiyanto, "Pengaruh Transformational Leadership , Reward Dan Work Engagement Terhadap Perilaku Kerja Pegawai Direktorat Jenderal Pendidikan Islam Kementerian Agama Ri," Jurnal Karya Abdi Volume 5, no. Nomor 1 Juni (2021): 18-28. 


\section{DAFTAR PUSTAKA}

Damayanti, S, and D A Rizal. "Pemanfaatan Sistem Informasi Pendidik Dan Tenaga Kependidikan (SIMPATIKA) Sebagai Dasar Pengambilan Keputusan Dan Kebijakan Di Kementerian Agama." Nusantara: Jurnal Pendidikan ... 1, no. 1 (2021): 77-94. https://journal.rumahindonesia.org/index.php/njpi/article/view/6.

Direktorat Jenderal Pendidikan Islam. "EMIS DASHBOARD." Kementerian Agama RI. Last $\begin{array}{llll}\text { modified } 2020 . & \text { Accessed July } 2021 .\end{array}$ http://emispendis.kemenag.go.id/dashboard/?content=datastatistik\&action=kab\&prov=35\&kab=14.

Direktorat Jenderal Pendidikan Islam Kementerian Agama RI. "SEJARAH PENDIDIKAN ISLAM DAN ORGANISASI DITJEN PENDIDIKAN ISLAM." Accessed July 9, 2021. http://pendis.kemenag.go.id/index.php?a=artikel\&id2=sejarahpendis.

Kementerian Pendidikan dan Kebudayaan. "DATA REFERENSI PENDIDIKAN." Pusat Data Dan Teknonologi Informasi. Last modified 2020. Accessed July 12, 2021. https://referensi.data.kemdikbud.go.id/index11.php?level=3\&kode=051902\&id=9.

Presiden Republik Indonesia. Undang-Undang Republik Indonesia Nomor 20 Tahun 2003 Tentang Sistem Pendidikan Nasional. Indonesia, 2003.

Seksi Integrasi Pengolahan dan Diseminasi Statistik. "Kecamatan Tutur Dalam Angka 2018." Peta Wilayah Kecamatan Tutur. BPS Kabupaten Pasuruan, 2018.

Seta, Henki Bayu, and Theresiawati Theresiawati. "Pelatihan Dan Pendampingan Aplikasi Data Pokok Pendidikan Untuk Operator Sekolah Pendidikan Anak Usia Dini." JURNAL ABDIMAS BSI 4, no. 1 (2021): 75-82.

Sisdiyanto, M Sidik. "Pengaruh Transformational Leadership , Reward Dan Work Engagement Terhadap Perilaku Kerja Pegawai Direktorat Jenderal Pendidikan Islam Kementerian Agama Ri." Jurnal Karya Abdi Volume 5, no. Nomor 1 Juni (2021): 18-28.

Sri Erny Muliyani, and Hj. Husnul Jannah. "Pengaruh Kualitas Pelayanan Operator Madrasah Terhadap Kepuasan Kerja Guru Madrasah Aliyah Plus Nurul Islam Sekarbela Kota Mataram." In Prosiding Seminar Nasional Lembaga Penelitian Dan Pendidikan (LPP) Mandala Tema Membangun Pendidikan Yang Mandiri Dan Berkualitas Pada Era Revolusi Industri 4.0, 393-404. Mataram: Universitas Muhammadiyah Mataram, 2018.

Susanti.R, Meri, Slamet Widodo, and Praningrum. "PENGARUH KEPEMIMPINAN DAN KEPRIBADIAN TERHADAP WORK ENGAGEMENT TENAGA KEPENDIDIKAN." al-Bahtsu Vol. 4, no. No. 2 Desember (2019): 166-175.

Tupono, Wahir. "Efektivitas Education Management Information System (Emis) Di Madrasah Aliyah Negeri 5 Sleman." Jurnal Manajemen Publik \& Kebijakan Publik (JMPKP) 2, no. 1 (2020): 24-37. 